2. Li Y, Sheu C-C, Ye Y, et al. Genetic variants and risk of lung cancer in never smokers: a genome-wide association study. Lancet Oncol 2010;11:321-30

3. Young RP, Hopkins RJ, Gamble GD, et al. Genetic evidence linking lung cancer and COPD: a new perspective. Appl Clin Genet 2011:4:1-13.

4. Young RP, Hopkins RJ, Etzel C, et al. Genetics of lung cancer susceptibility and COPD. Lancet Oncol 2011:12:622-3.

5. Hopkins RJ, Young RP, Hay B, et al. Gene-based lung cancer risk score triggers smoking cessation in randomly recruited smokers. Am J Respir Crit Med 2011;183:A5441.

\section{Chest drain insertion - training is the key, Seldinger or otherwise}

We welcome Maskell et al's timely editorial highlighting the shortfalls of safe chest drain insertion. ${ }^{1}$ Modernising Medical Careers states that competence in chest drain insertion should be achieved as a part of core medical training but does not set out how this might be practically achieved. The authors suggest that chest drain insertion should not be a generic skill but be confined to respiratory teams. Where there is a large presence of chest physicians, this may be possible. Few hospitals can achieve this. Where all chest drains cannot be inserted by the chest team, all registrars who take part in unselected acute medical take service should be trained.

Our trust, with seven chest physicians, has over the past 3 years addressed training by developing and validating a training module for chest drain insertion using a Porcine-Resin model. The module focuses on decision making and simulation training using the model with assessment using a direct observation of procedural skills; a session takes $4 \mathrm{~h}$. Before proceeding to perform independently on patients, close supervision with feedback is provided until the trainee is deemed competent and confident. The West Midlands Deanery recognising the importance of training has funded a Teaching Fellow to train all Core Medical Trainees in the region using the module. We also run a training day for newly appointed Respiratory Registrars (ST3) as they lack experience and feel vulnerable.

The National Patient Safety Agency (NPSA) report ${ }^{2}$ in May 2008 highlighted the risks associated with chest drain insertion. We conducted a postal survey of Lead Chest Physicians in all acute hospitals in England and Wales in August 2009, which showed training sessions and competency assessment were established in only 58 of the 110 hospitals that responded to the survey. There was no register of competent trainees in $76 \%$ of the departments. The NPSA's recommen- dation on pleural procedures audits has only been implemented by $55 \%$ of the hospitals, 1 year on.

As we uphold the mantra 'It is not the gun that is dangerous, it's the person holding it', regular training courses need to be a formal part of the training curriculum and respiratory consultants' time should be recognised in their job plans.

\section{Thirumalai Rengarajan Naicker, Dwight Thomas McLeod}

Sandwell and West Birmingham NHS Trust, Birmingham, UK

Correspondence to Dr Thirumalai R Naicker, Princess Royal Hospital, Apley Castle, Telford, TF1 6TF, UK; drnaicker@yahoo.co.uk

Competing interests None.

Provenance and peer review Not commissioned; externally peer reviewed.

Accepted 5 April 2010

Published Online First 21 July 2011

Thorax 2011;66:1013

doi:10.1136/thx.2010.138016

\section{REFERENCES}

1. Maskell NA, Medford A, Gleeson FV. Seldinger chest drain insertion: simpler but not necessarily safer Thorax 2010:65:5-6.

2. Rapid response report, NPSA/2008/RRR003. 